\title{
Odontogenic sinusitis among patients surgically treated for maxillary sinus disease*
}

\author{
B.B. Philipsen', S. Ghawsi², A.D. Kjeldsen ${ }^{1,3}$ \\ Department of Otorhinolaryngology-Head and Neck surgery, Odense University Hospital, Denmark \\ 2Department of Oral Maxillofacial Surgery, Odense University Hospital, Denmark \\ ${ }^{3}$ Clinical institute University of Southern Denmark
}

Rhinology Online, Vol 1: 60 - 66, 2018

http://doi.org/10.4193/RHINOL/18.004

*Received for publication:

January 22, 2018

Accepted: May 23, 2018

Published: June 10, 2018

\begin{abstract}
Objective: To report the underlying cause and occurrence of odontogenic disease among patients requiring treatment for chronic maxillary sinusitis in a University Hospital setting in Denmark.

Study design: This is a retrospective study including all patients referred for surgical treatment of chronic maxillary sinusitis in the period January 1st, 2000 - December 1st, 2009. All files where reviewed and any concealed odontogenic cause was identified. Demographic data and clinical aspects including duration of illness, radiographic data and prior therapies were assessed. A telephone interview was performed as follow-up.
\end{abstract}

Results: Files from 788 patients treated with surgery for their maxillary sinus disease were evaluated and among 37 patients an odontogenic origin of sinus disease was identified. Of these $81.1 \%$ participated in the telephone interview with the majority of patients reporting symptom improvement after the treatment. There were no major complications. The most common cause of odontogenic sinusitis was complication to tooth extraction. Diagnostic delay was common, $32 \%$ had experienced symptoms more than a year.

Conclusion: According to the conducted survey, $4.7 \%$ of patients treated for maxillary sinus disease suffered from an underlying dental disease. In patients with Chronic Rhino Sinusitis (CRS) it is important to gather history of dental disease and prescribe evaluation by a maxillofacial surgeon especially in case of recalcitrant disease.

Key words: maxillary sinusitis, chronic maxillary sinusitis, odontogenic sinusitis, dental disease/ complications, periodontitis, oroantral fistula

\section{Introduction}

Patients with CRS suffer from nasal blockage, obstruction, congestion with or without facial pain or reduced sense of smell. The symptoms are caused by inflammation of the nasal and paranasal mucosa often in relation to an acute rhinitis. CRS is defined as present when symptoms have lasted for $>12$ weeks ${ }^{(1)}$. In these cases, anterior rhinoscopy or more detailed endoscopy should be performed to identify secretion, edema or polyps.

\begin{abstract}
Most cases of CRS can be controlled by medical and surgical treatment; however some patients develop recalcitrant infections. Recalcitrant CRS imposes a huge problem for the afflicted patients. Dental disease, foreign body, immunosuppression and fungus disease are considered to be some of the important causes of recalcitrant CRS ${ }^{(1,2)}$.
\end{abstract}

Most patients with CRS have bilateral problems ${ }^{(3)}$ but in some

Abbreviations: Caldwell-Luc, Radical antrum operation; CRS: Chronic Rhino Sinusitis; CT: Computed tomography; Lothrop-Claoué: Rhino-AntroStomy; Rhermann Plastic: Mobilization of the buccal flap for primary closure +/- buccal fat; PET: Positron emission tomography scan; Schneiderian membrane: Membranous lining of the maxillary sinus cavity 
cases, the problems are unilateral. Especially in these cases, it is important for the physician to acknowledge other causes of maxillary sinusitis than nasal disease. A common cause of unilateral maxillary sinusitis is odontogenic sinusitis. Studies show that up to $12-14 \%$ of CRS has an odontogenic ethology ${ }^{(4-6)}$. However, recent studies indicate that the actual number may be up to $25-40 \%$ of patients ${ }^{(5,7-9)}$.

In this study we report the underlying cause and occurrence of odontogenic disease among patients, requiring treatment for chronic maxillary sinusitis in a University Hospital setting in Denmark. Additionally, we estimate the time from debut of symptom until the correct diagnosis was made.

\section{Methods}

\section{Study design}

The study is a retrospective study, with focus on dental causes for sinus surgery, including a telephone interview as follow-up. Odense University Hospital has an OMFS (Oral and Maxillofacial surgical) department and an ENT department, which are involved in and responsible for the treatment of odontogenic sinusitis in an interdisciplinary diagnostic setting. All patients who had maxillary sinus surgery performed in the 10-year period January 1st, 2000 to December 31st, 2009 were identified using surgical ICD 10 codes (DMB20 DNB20 DMW00 KPDM10 UDM05 DMB00).

The charts were reviewed according to age, gender, symptoms, date of the first consultation at Odense University Hospital, date of surgery, type of surgery, postoperative complications and treatment results. Most cases were without any sign of odontogenic cause. Cases of doubt were discussed between ADK and BBP. Patients with chronic maxillary sinusitis of odontogenic origin diagnosed on a clinical and radiological base were included. These patients had all been evaluated by either their private dentist or the Hospital OMFS. The etiological promoter responsible for the onset of this disease was recorded and analyzed to establish its frequency. As part of the quality assessment at the department, all patients with odontogenic sinusitis were contacted by telephone and interviewed regarding long-term treatment results and long-term complications. The patients were asked following questions. Were you satisfied with the surgical treatment? Do you still have any of the same symptoms as before surgery? Did you have any early or late complications after the surgery? The results of surgery were considered good if the patient was free of symptoms such as nasal discharge, nasal obstruction, edema and facial pain and if an oroantral fistula had healed completely.

\section{Statistics}

The data were statistically analyzed using Statistical Package of Microsoft Excel Software.

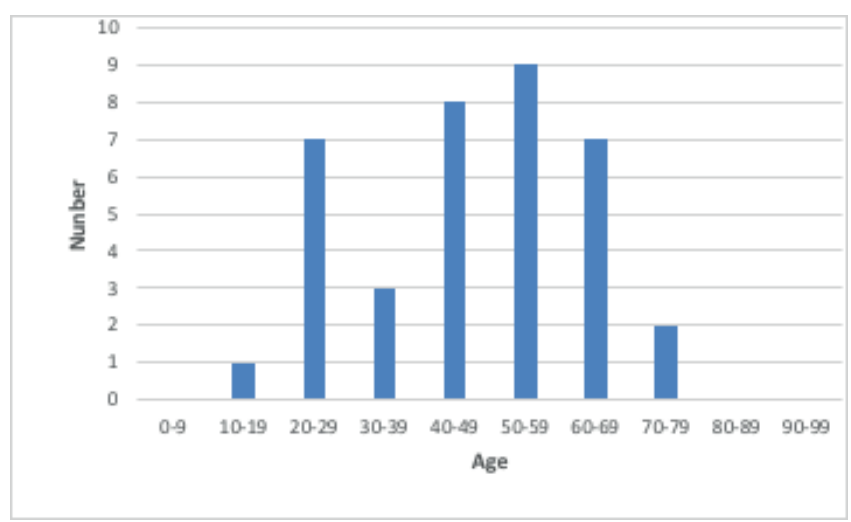

Figure 1. The 37 patients treated for odontogenic sinusitis according to age.

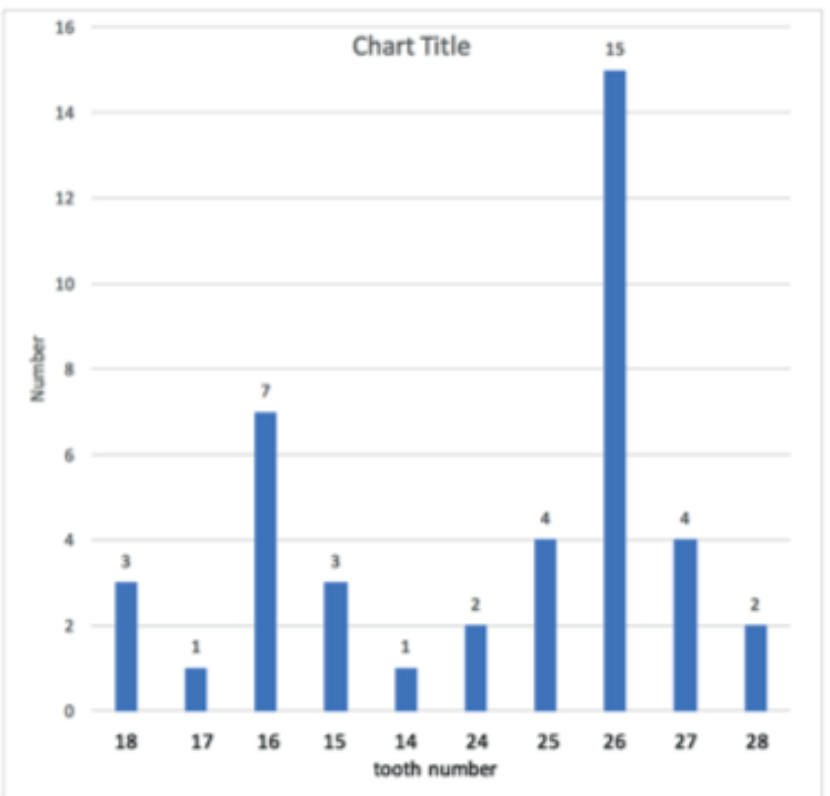

Figure 2. The figure shows which tooth was involved in the 37 cases with odontogenic maxillary sinusitis.

\section{Ethics}

We contacted the patients as a part of a quality assurance project. We did not change the treatment. The National Committee on Health Research Ethics approved our project in 2010.

\section{Results}

In total, 788 patients with CRS had maxillary sinus surgery performed during the specified time period. A concomitant odontogenic disease was identified in 37 cases ( 19 men and 18 female) (Figure 1). The median age of the patients was 47.3 years (range 17-71 years) (Figure 1). Prevalence of suspected dental cause was $4.7 \%$ of all treated patients. No bilateral cases were identified.

In relation to the etiology (Table 1), tooth extraction and root canal treatment were the most common treatments suspected as responsible for odontogenic sinusitis. Other possible etiolo- 
Table 1. Dental origin of sinusitis in 37 patients.

\begin{tabular}{|l|c|}
\hline \multicolumn{1}{|c|}{ Cause of odontogenic sinusitis } & $\begin{array}{c}\text { Number of } \\
\text { patients }\end{array}$ \\
\hline Tooth extraction & 10 \\
\hline Root canal treatment & 5 \\
\hline $\begin{array}{l}\text { Extrusion of endodontic obturation materials into } \\
\text { sinus }\end{array}$ & 2 \\
\hline Incorrectly positioned dental implants & 2 \\
\hline Dental abscesses & 5 \\
\hline Retained teeth & 3 \\
\hline Poor dental hygiene & 3 \\
\hline Oroantral fistula & 3 \\
\hline Periodontitis & 2 \\
\hline Unknown cause & 2 \\
\hline
\end{tabular}

Table 2. Duration of symptoms before the first consultation at Odense University Hospital.

\begin{tabular}{|c|c|c|}
\hline $\begin{array}{l}\text { Duration of symptoms be- } \\
\text { fore the first consultation }\end{array}$ & $\begin{array}{l}\text { Number of } \\
\text { patients }\end{array}$ & Percentage \\
\hline Less than 10 days & 5 & $13.5 \%$ \\
\hline One month & 3 & $8.1 \%$ \\
\hline Three months & 6 & $16.2 \%$ \\
\hline Six months & 5 & $13.5 \%$ \\
\hline One years & 6 & $16.2 \%$ \\
\hline Two years & 2 & $5.4 \%$ \\
\hline Three years & 1 & $2.7 \%$ \\
\hline Four years & 2 & $5.4 \%$ \\
\hline 10 years & 1 & $2.7 \%$ \\
\hline Unknown period & 6 & $16.2 \%$ \\
\hline
\end{tabular}

gies included: poor dental hygiene, periodontitis and retained teeth. Complications to dental treatment were the suspected cause of odontogenic sinusitis in $51.3 \%$ of the patients in this study. A significant higher complication rate was observed to treatments in the upper left jaw representing $64.3 \%$ of the cases of which tooth 26 was involved in $36 \%$ of the cases overall (Figure 2).

The patients suffered from a variety of symptoms with pain being the dominating symptom. $73.0 \%$ had pain localized to the involved sinus, $56.8 \%$ purulent nasal discharge, $24.3 \%$ nasal obstruction, $18.9 \%$ edema, $8.1 \%$ fever and $10.8 \%$ other symptoms. In 18 of the cases in this study, radiographic examination included a combination of ortopan tomography and computed tomography (CT) (48.6\%), nine (24.3\%) only had ortopan tomography and 8 (21.6\%) only had CT. In one case $(2.7 \%)$ no radiological examination was performed and in one case $(2.7 \%)$ results from a positron emission tomography (PET) was used.

\section{Treatments before the first consultation}

Characteristic for the majority of patients in this study (22 patients $=59.4 \%$ ) was a slight response to initial medical therapy or other treatments with long intervals of remission but recurrence of symptoms.

Before the first consultation at Odense University Hospital, 19 patients were treated with antibiotic with or without different kinds of surgeries (51.4\%). In 14 patients, no treatment had been initiated. 12 patients (32\%) had suffered from symptoms at least one year before the first consultation at Odense University Hospital (Table 2).

\section{Surgical treatment}

The surgical treatment was in the majority of cases performed as joint venture procedure including ENT and OMFS. The first surgical step was to identify the odontogenic source and implement this in a treatment strategy. A throughout description is available in table 3 . The surgical sinus treatment included transnasal endoscopic surgery in 22 cases (59.5\%), Lothrop-Claoue procedure (Rhino-Antro-Stomy) in seven cases (18.9\%) and a Caldwell-Luc procedure (radical antrum operation) in two cases (5.4\%). Puncture and irrigation of the maxillary sinus had been performed in five cases (13.5\%). Sinoscopy and biopsy was used in one case. All surgical sinus treatments were performed under general anesthesia.

\section{Postoperative medicament treatment}

In 14 patients (37.8\%) treatment with nasal steroid over a period of one to three months after the surgery had been prescribed, one patient had received systemic steroid therapy and in 17 cases (45.9\%) postoperative antibiotic treatment had been prescribed.

\section{Postoperative complications}

There were no recorded major postoperative complications. Only minor complications such as bleeding, infection or pain were seen in seven cases (18.9\%).

\section{Follow up interview}

Thirty patients ( $81.1 \%$ ) were interviewed by telephone. The median follow-up time between surgery and telephone interview was 52 months (Range, 8-122 months). We were not able to get in touch with two patients and four patients would not participate, one patient was dead. The results of surgery were considered good if the patient was free of symptoms such as nasal discharge, nasal obstruction, edema and facial pain and 
Table 3. The odontogenic sources and the treatment.

\begin{tabular}{|c|c|c|c|c|}
\hline & $\begin{array}{l}\text { Causes of odontogenic maxil- } \\
\text { lary sinusitis }\end{array}$ & $\begin{array}{l}\text { The odontogenic } \\
\text { source }\end{array}$ & Dental surgery & Sinus surgery \\
\hline & \multicolumn{4}{|l|}{ Tooth extraction } \\
\hline 1 & Tooth extraction & 26 & None & $\begin{array}{l}\text { Transnasal endoscopic surgery radix } \\
\text { relictae removal from sinus }\end{array}$ \\
\hline 2 & Tooth extraction & 26 & Amotio radix & $\begin{array}{l}\text { Puncture and irrigation of the maxillary } \\
\text { sinus }\end{array}$ \\
\hline 3 & Tooth extraction & 26 & None & Transnasal endoscopic surgery \\
\hline 4 & Tooth extraction & 26 & Rehrmann plastic & Claoue \\
\hline 5 & Tooth extraction & $16+26$ & Rehrmann plastic & Claoue \\
\hline 6 & Tooth extraction & 16 & None & $\begin{array}{l}\text { Transnasal endoscopic surgery radix } \\
\text { relicta16 from sinus maxillaris }\end{array}$ \\
\hline 7 & Tooth extraction & 27 & $\begin{array}{l}\text { Oroantral fistula closure ad modum } \\
\text { Rehrmann }\end{array}$ & Claoue \\
\hline 8 & Tooth extraction & Unknown molar & Treatment by own dentist & Transnasal endoscopic surgery \\
\hline 9 & Tooth extraction & Unknown molar & Spontaneus closure of oroanteral fistula & Transnasal endoscopic surgery \\
\hline \multirow[t]{2}{*}{10} & Tooth extraction & $17+18$ & Rehrmann plastic & Claoue \\
\hline & \multicolumn{4}{|l|}{ Root canal treatment } \\
\hline 1 & Root canal treatment & 15 & $\begin{array}{l}\text { Root canal cement residual removal } \\
\text { Rehrmann plastic }\end{array}$ & Luc Caldwell \\
\hline 2 & Root canal treatment & 15 & Apisectomi and retrograde filling & Transnasal endoscopic surgery \\
\hline 3 & Root canal treatment & 26 & Extraction of displaced root canal filling & Transnasal endoscopic surgery \\
\hline 4 & Root canal treatment & 26 & Extraction Rehrmann plastic & Claoue \\
\hline 5 & Root canal treatment & Unknown molar & None & $\begin{array}{l}\text { Transnasal endoscopic surgery Dental } \\
\text { wax material removal }\end{array}$ \\
\hline & \multicolumn{4}{|l|}{ Periapical dental abscess } \\
\hline 1 & Periapical dental abscess & 14 & Treatment in primary sector & $\begin{array}{l}\text { Puncture and irrigation of the maxillary } \\
\text { sinus }\end{array}$ \\
\hline 2 & Periapical dental abscess & 16 & Root canal treatment in primary sector & Transnasal endoscopic surgery \\
\hline 3 & Periapical dental abscess & 18 & Tooth extraction & $\begin{array}{l}\text { Puncture and irrigation of the maxillary } \\
\text { sinus }\end{array}$ \\
\hline 4 & Periapical dental abscess & $26+27$ & Tooth extraction & Transnasal endoscopic surgery \\
\hline 5 & Periapical dental abscess & 27 & Tooth extraction & $\begin{array}{l}\text { Puncture and irrigation of the maxillary } \\
\text { sinus }\end{array}$ \\
\hline & \multicolumn{4}{|l|}{ Dens retentus } \\
\hline 1 & Dens retentus & 18 & $\begin{array}{l}\text { Amotio dens retentus. Keratocystis } \\
\text { removal. Recidiv of keratocystis and } \\
\text { new surgery }\end{array}$ & $\begin{array}{l}\text { Puncture and irrigation of the maxillary } \\
\text { sinus }\end{array}$ \\
\hline 2 & Dens retentus & 18 & Amotio dens retentus & $\begin{array}{l}\text { Sinuscopy and biopsy (Cystis follicu- } \\
\text { laris) }\end{array}$ \\
\hline 3 & Dens retentus & 28 & Amotio dens retentus & Luc-Caldwell; Sinus cyst removal \\
\hline & \multicolumn{4}{|l|}{ Periodontitis } \\
\hline 1 & Periapical periodontitis & 16 & Tooth extractionRerhmann plastic & Claoue \\
\hline 2 & Juvenile periodontitis & 26 & Tooth extraction & Transnasal endoscopic surgery \\
\hline & \multicolumn{4}{|l|}{ Oroantral fistula } \\
\hline 1 & $\begin{array}{l}\text { Oroantral fistula (Sequalae after } \\
\text { orbita fracture in 1982) }\end{array}$ & 26 & Rerhmann plastic & Transnasal endoscopic surgery \\
\hline 2 & $\begin{array}{l}\text { Oroantral fistula (Complication } \\
\text { to bilateral sinus lift and auto- } \\
\text { log tibia bone transplantation) }\end{array}$ & 26 & Rerhmann plastic & Transnasal endoscopic surgery \\
\hline 3 & Oroantral fistula & 27 & Rerhmann plastic & Transnasal endoscopic surgery \\
\hline
\end{tabular}




\begin{tabular}{|c|c|c|c|c|}
\hline & $\begin{array}{l}\text { Causes of odontogenic maxil- } \\
\text { lary sinusitis }\end{array}$ & $\begin{array}{l}\text { The odontogenic } \\
\text { source }\end{array}$ & Dental surgery & Sinus surgery \\
\hline & \multicolumn{4}{|l|}{$\begin{array}{l}\text { Incorrectly positioned } \\
\text { implants }\end{array}$} \\
\hline 1 & Incorrectly positioned implants & 24 & Implant removal Rerhmann plastic & Transnasal endoscopic surgery \\
\hline \multirow[t]{2}{*}{2} & Incorrectly positioned implants & $25+26$ & Implant removal & Transnasal endoscopic surgery \\
\hline & \multicolumn{4}{|l|}{ Poor dental status } \\
\hline 1 & Poor dental status & $24-26$ & Tooth extraction; Rerhmann plastic & $\begin{array}{l}\text { Transnasal endoscopic surgery Sinus } \\
\text { cyst removal }\end{array}$ \\
\hline 2 & Poor dental status & $25+26$ & Treatment in primary sector & Transnasal endoscopic surgery \\
\hline \multirow[t]{2}{*}{3} & Poor dental status & $27+28$ & Tooth extraction & $\begin{array}{l}\text { Transnasal endoscopic surgery Drai- } \\
\text { nage }\end{array}$ \\
\hline & \multicolumn{4}{|l|}{$\begin{array}{l}\text { Extrusion of obturation mate- } \\
\text { rials into sinus }\end{array}$} \\
\hline 1 & $\begin{array}{l}\text { Extrusion of temporary cement } \\
\text { into sinus }\end{array}$ & $15+16$ & Root canal treatment & $\begin{array}{l}\text { Transnasal endoscopic surge obtura- } \\
\text { tion material removal }\end{array}$ \\
\hline \multirow[t]{2}{*}{2} & $\begin{array}{l}\text { Extrusion of dental cast acryl } \\
\text { into sinus }\end{array}$ & 16 & Dental cast acryl material removal & Transnasal endoscopic surgery \\
\hline & \multicolumn{4}{|l|}{ Unknown cause } \\
\hline 1 & Unknown cause & 16 & Amotio dentis & Transnasal endoscopic surgery \\
\hline 2 & Unknown cause & $25+26$ & Treatment in primary sector & Transnasal endoscopic surgery \\
\hline
\end{tabular}

\section{Discussion}

maxillary sinusitis from OMFS department.

Diagnostic tools include radiographic examination and inn most of the cases in this study, radiographic examination included a combination of ortopantomography and CT in order to plan a safe surgical procedure.

A review has suggested that Cone Beam Volumetric Computed Tomography (CBCT) is indicated in cases of odontogenic maxillary sinusitis not being responsive to therapy ${ }^{(17)}$. Cone Beam CT is a relatively new tool which utilizes approximately $10 \%$ of the radiation dose of conventional $\mathrm{CT}$, and is able to image bony detail exquisitely, although soft tissue detail is reduced ${ }^{(18)}$. Cone Beam was not available at our institution in the study period. The majority of patients were therefore examined with ortopantomography and/or CT scanning of paranasal sinus.

Complications to dental treatment were the suspected cause of odontogenic maxillary sinusitis in $51.3 \%$ of the patients in this study, while other etiological factors such as periodontitis were less frequent. In other studies, odontogenic infections are considered the most common cause of odontogenic sinusitis ${ }^{(19)}$. This difference in occurrence may possible relate to a better oral health in Denmark. Improved oral health should imply a decreased risk of dental infection.

However, our study shows a wide range of factors indicating, that even in regions with high oral health care odontogenic sinusitis should still be considered a risk. Even so, these may often be caused by advanced and technically challenging dental procedures in all age groups.

One of the common causes of odontogenic sinusitis is the pre- sence of an oroantral fistula after tooth extraction. An oroantral fistula is defined as an osteomucosal communication between the oral cavity and either a sinus or the nasal cavity. Treatment of these lesions should be performed in close cooperation between ENT and dental surgeons ${ }^{(13,20)}$. The treatment of oroantral fistula and maxillary sinusitis of odontogenic origin is surgical. The surgeons in this study used a combination of primary closure ad modem Rhermann Plastic with or without buccal fat and sinus surgery.

Foreign bodies in the maxillary sinus such as root canal cement,

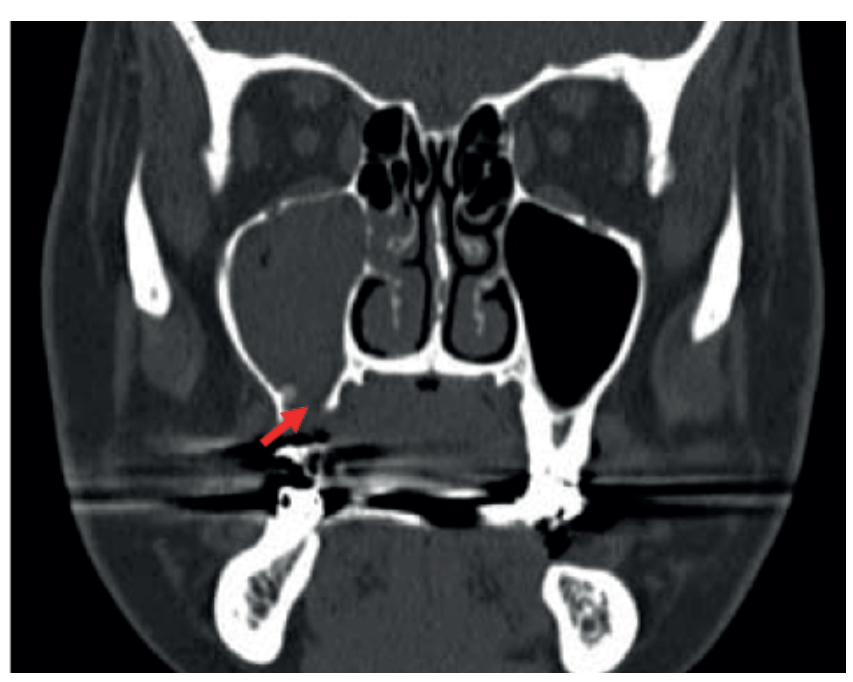

Figure 3. A presurgery $\mathrm{CT}$. The coronal image shows the right maxillary sinus with an oroantral fistula on the inferior wall of the maxillary sinus. 
parts of tooth, and parts of bone were the cause of disease in a number of cases. In all these cases removal of the foreign body solved the problem for the patient.

Table 3 shows that the treatment of odontogenic sinusitis involves several different surgical procedures. In this study Claoue was the most common surgical sinus treatment of oroantral fistula. Transnasal endoscopic surgery was also used in treatment of oroantral fistula. Transnasal endoscopic surgery is a safe technique with a lower risk of complications ${ }^{(13)}$. The Claoue procedure has now in the majority of cases been replaced by endoscopic opening of the maxillary sinus because of less traumatic approach and lower rate of complications and better preservation of antral lining.

Endoscopic opening of the maxillary sinus has gained popularity against Caldwell Luc procedure in treatment of odontogenic maxillary sinusitis, and is the first choice for treating chronic sinusitis. In very rare cases Caldwell Luc procedure could be considered to access disease of anterior maxillary sinus wall No major complications such as orbital hematoma, visual disturbance and cerebrospinal fluid leak or trigeminal neuralgia were observed during or after the sinus surgery in this study. The follow up interview indicated good results of surgical treatment of the odontogenic maxillary sinusitis and no major early or long term complications.

\section{Conclusion}

Characteristic for odontogenic maxillary sinusitis is persistence of symptoms for a long period, and a rather long diagnostic delay before diagnosis was made. Odontogenic origin of infection must be suspected in sinusitis patients who are resistant to standard medical or surgical treatment as well as in those who have a history of dental problems or dental or oral surgical treatment.
The percentage of patients requiring surgery for a (unilateral) odontogenic maxillary sinusitis disease in Odense University Hospital setting (tertiary center) was $4.7 \%$ of the total surgical population undergoing surgery involving the maxillary sinus (788 patients).

latrogenic causes, which include dental extractions, were the most common etiologic factors related to the development of odontogenic maxillary sinusitis in this study. Complications to dental treatment were responsible for a majority (51.3\%) of the cases of odontogenic sinusitis.

In this study the non-surgical treated population is not reviewed, and we cannot conclude from this study alone that management of maxillary sinus disease of odontogenic origin requires surgical drainage/sinus surgery.

We can conclude that the management of maxillary sinus disease of odontogenic origin in Odense University Hospital setting may require surgical drainage/sinus surgery, and treatment to remove the offending dental etiology.

\section{Acknowledgement}

Thanks to the patients who participated in the telephone interview.

\section{Authorship contribution}

Concept and design, Analysis and interpretation of data: BBP; Drafting manuscript or revision: All authors; All authors gave final approval of the version to be published.

\section{Conflict of interest}

The authors declare that they have no conflict of interest.

\section{References}

1. Fokkens WJ, Lund VJ, Mullol J, et al. European position paper on rhinosinusitis and nasal polyps 2012. A summary for otorhinolaryngologists. Rhinology. 2012 Mar;50(1):1-12

2. Prokopakis EP, et al. SCUAD and chronic rhinosinusitis. Reinforcing hypothesis driven research in difficult cases. Rhinology. 2014 Mar;52(1):3-8

3. Lee JY, Byun JY, Shim SS, Lee SW. Outcomes after endoscopic sinus surgery for unilatera versus bilateral chronic rhinosinusitis with nasal polyposis. Am J Rhinol Allergy. 2010 May;24(3):83-6

4. Mehra P, Murad H. Maxillary sinus disease of odontogenic origin. Otolaryngol Clin North Am. 2004 Apr; 37(2):347-64

5. Simuntis $R$, Ricardas $K$, Vaitkus $S$. Odontogenic maxillary sinusitis: A review. Stomatologija, Baltic Dental and
Maxillofacial Journal. 2014;16:39-43.

6. Akhlaghi F, Esmaeelinejad M, Safai P. Etiologies and Treatments of Odontogenic Maxillary Sinusitis: A Systematic Review. Iran Red Crescent Med J. 2015 Dec;17(12): e25536.

7. Taschieri S, Torretta S, Corbella S, Del Fabbro M, Francetti L, Lolato A, Capaccio P. Pathophysiology of sinusitis of odontogenic origin. J Investigative Clin Dent. 2015 July;8:e12202.

8. Patel N, Ferguson B. Odontogenic sinusitis: an ancient but underappreciated cause of maxillary sinusitis. Curr Opin Otolaryngol Head Neck Surg. 2012 Febr;20:24-28.

9. Hauman $\mathrm{CHJ}$, Chandler NP, Tong DC Endodontic implications of the maxillary sinus. International Endodontics J. 2002 Oct;35:127-141

10. Hellings PW, et al. EUFOREA Rhinology Research Forum 2016: report of the brain- storming sessions on needs and priorities in rhinitis and rhinosinusitis. Rhinology. 2017 Sep 1;55(3):202-210

11. Brook I. Sinusitis of odontogenic origin. Otolaryngol Head Neck Surg. 2006;135:349355.

12. Ugincius P, Kubilius R, Gervickas A, Vaitkus S., Chronic odontogenic maxillary sinusitis. Stomatologija, 2006 8:44-8.

13. Hajiioannou J, Koudounarakis $E$, Alexopoulos K, Kotsani A, Kyrmizakis DE. Maxillary sinusitis of dental origin due to oroantral fistula, treated by endoscopic sinus surgery and primary fistula closure. J Laryngol Otol. 2010 Sep;124(9):986-9.

14. Albu S, Baciut M. Failures in endoscopic surgery of the maxillary sinus. Otolaryngol Head Neck Surg 2010 February;142 (2) 196201

15. Christensen LB, Twetman S, Sundby A. Oral health in children and adolescents with 
different socio-cultural and socio-economic backgrounds. Acta Odontol Scand. 2010 Jan;68(1):34-42.

16. http://www.expatindenmark.com/infocentre/forexpats/Pages/HealthCare.aspx

17. Shahbazian M, Jacobs R. Diagnostic value of $2 \mathrm{D}$ and $3 \mathrm{D}$ imaging in odontogenic maxillary sinusitis: a review of literature. J Ora Rehabil. 2012 Apr;39(4):294-300.

18. Schulze D, Heiland M, Thurmann H Radiation exposure during midfacial imaging using 4 and 16 slice computed tomography, cone beam computed tomography systems and conventional radiography. Dentomaxillofac Radiol. 2004;33:83-6.

19. Legert KG, Zimmerman M, Stierna $P$. Sinusitis of odontogenic origin: pathophysiological implications of early treatment.
Acta Otolaryngol. 2004 Aug;124(6):655-63.

20. Mehra P, Jeong D. Maxillary sinusitis of odontogenic origin. Curr Allergy Asthma Rep. 2009 May;9(3):238-43.

Bahareh Bakhshaie Philipsen

Otorhinolaryngology

Head and Neck surgery

Odense University Hospital

Sdr. Boulevard 29

5000 Odense $C$

Denmark

Tel: +4531329298

Fax: +4566192615

E-mail: Bahareh.bakhshaie.philipsen@rsyd.dk 